\title{
Behavior of CuPb12Sn6 Alloys subjected to Heat Treatments
}

\author{
Dragoș Cristian Achiței ${ }^{1, *}$, Mirabela Georgiana Minciună ${ }^{1}$, Mohd Mustafa Al bakri \\ Abdullah $^{2,3}$, Andrei Victor Sandu ${ }^{1}$, Michal Szota ${ }^{4}$ and Petrică Vizureanu ${ }^{1}$ \\ ${ }^{1}$ Department Technologies and Equipments for Materials Processing, Gheorghe Asachi Technical \\ University of Iasi, D Mangeron Street, no 41 A, Iasi \\ ${ }^{2}$ Faculty of Engineering Technology, Universiti Malaysia Perlis, Kangar, Perlis, Malaysia \\ ${ }^{3}$ Center of Excellence Geopolymer \& Green Technology (CEGeoGTech), School of Materials \\ Engineering, Universiti Malaysia Perlis, Kangar, Perlis, Malaysia \\ ${ }^{4}$ Czestochowa University of Technology, Institute of Materials Science and Engineering, 19 Armii \\ Krajowej Av., Czestochowa, Poland
}

\begin{abstract}
The paper present the structural modifications induced by 3 heat treatments: homogenization, recrystallization and quenching, respecting the specific parameters of copper based alloys. The obtained modifications by heat treatments were highlighted by micro-hardness measurements, with Vickers method, and by electronic structural microscopy, at various magnitudes.
\end{abstract}

\section{Introduction}

Copper is an excellent electrical conductor. Most of its uses are based on this property or the fact that it is also a good thermal conductor. However, many of its applications also rely on one or more of its other properties. For example, it wouldn't make very good water and gas pipes if it were highly reactive.

Copper is low in the reactivity series. This means that it doesn't tend to corrode. Again, this is important for its use for pipes, electrical cables, saucepans and radiators.

However, it also means that it is well suited to decorative use. Jewellery, statues and parts of buildings can be made from copper, brass or bronze and remain attractive for thousands of years.

Copper and its alloys, such as brass, are used for jewellery and ornaments. They have an attractive golden colour which varies with the copper content. They have a good resistance to tarnishing making them last a long a time.

Copper can be recycled without any loss of quality. $40 \%$ of the world's demand is met by recycled copper.

The alloying elements contribute to increase of their resistance properties, concomitant with the decrease of plasticity properties. The principal deficiencies of pure copper, like low castability, low corrosion resistance, mechanical properties at small values, can be removed partially or totally by alloying.

\footnotetext{
${ }^{*}$ Corresponding author: mirabela.minciuna@yahoo.ro
} 
Due his physical-chemical and mechanical properties, the copper and his alloys have much utilization in electrical engineering, chemical industry, aeronautics, oil industry, food industry (under forms of laminated, drawn and cast products).

Copper have 2 categories of alloys: brasses ( $\mathrm{Cu}-\mathrm{Zn}$ alloys and other elements) and bronzes $(\mathrm{Cu}-\mathrm{Sn}$ alloys and other elements).

The equilibrium diagram of $\mathrm{Cu}-\mathrm{Sn}$ alloys system is like diagrams with partial solubility in solid state and with peritectic and eutectoid transformations. The maximum solubility, in solid states, of $\mathrm{Sn}$ in $\mathrm{Cu}$ us by $15.8 \%$ at temperature by $520^{\circ} \mathrm{C}$, and is lowest than in the case of zinc and varies in function of temperature:

- At start, increase from $13.5 \%$ (at $768^{\circ} \mathrm{C}$ ) up to $15.8 \%$ (at $520^{\circ} \mathrm{C}$ ).

- Decrease to $13.9 \%$ at ambient temperature.

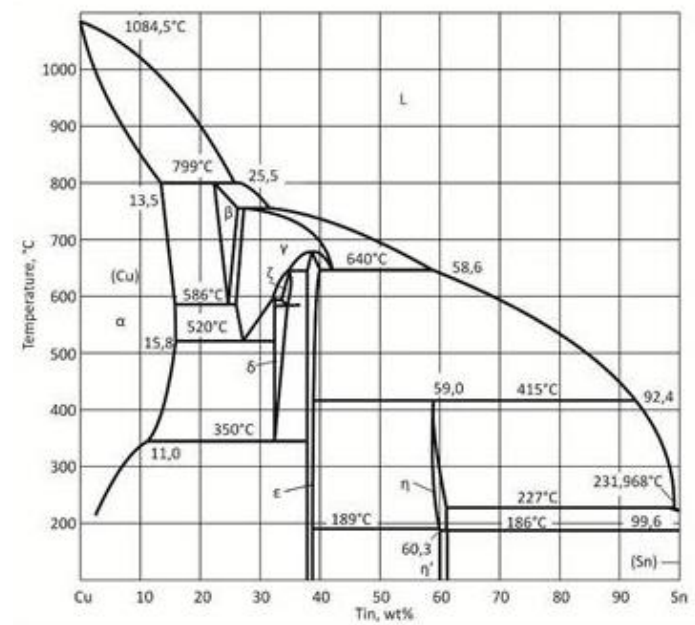

Fig. 1. The $\mathrm{Cu}-\mathrm{Sn}$ equilibrium diagram.

In the diagram can observe the following intermetallic phases:

- $\alpha$ phase - solid solution by substitution, isomorphic with copper, which crystallize in cubic system with centered faces;

- $\beta$ phase - solid solution, stabilized at high temperatures, up to $586^{\circ} \mathrm{C}$, based on electronic compound $\mathrm{Cu}_{5} \mathrm{Sn}$, with $\frac{n_{e}}{n_{a}}=\frac{3}{2}$ ratio;

- $\gamma$ phase - stabilized only the high temperature, up to $586{ }^{\circ} \mathrm{C}$, resulted by redistribution of the atoms in crystalline network of $\gamma$ phase;

- $\delta$ phase - represent the electronic compound $\mathrm{Cu}_{31} \mathrm{Sn}_{8}$, cu cubic crystalline network, with electronic concentration by $21 / 13$.

\section{Experiments}

\subsection{Determination of chemical composition}

The determination of alloying elements percents was made on Foundry Masters optical spectrometer, using copper base for analysis. The experimental tests were realized on samples which were prepared by polishing on abrasive papers.

The analyzed alloy is part of $\mathrm{Cu}-\mathrm{Pb}-\mathrm{Sn}$ alloys class (alloyed bronze) and is fall in the standard limits of $\mathrm{CuPb} 12 \mathrm{Sn} 6$ alloy.This type of alloy present a structure formed by copper grains, in which are dispersed lead particles. 
Whereas the mechanical resistance of binary bronzes is low, it is used lead bronzes which are alloyed with tin, nickel and zinc. The tin increase the mechanical resistance, the zinc hardened the base mass, and nickel smooth the repartition of lead particles.

$\mathrm{The} \mathrm{Cu}-\mathrm{Pb}-\mathrm{Sn}$ antifriction bronzes are sufficient by mechanical resistant; to be use like bearings, without protected enclosures by steels, when support pressures by $6000 \mathrm{~N} / \mathrm{cm}^{2}$. These bronzes have high corrosion resistance, and good usage resistance. This alloy is use at plain bearings for calenders, vehicles, mill, bearings, bolts for pistons, bushings for wheel drive, brake discs, usage resistant parts, corrosion resistant parts in water and armatures resistant in acid medium.

\subsection{The heat treatments applied to $\mathrm{Cu}-\mathrm{Pb}-\mathrm{Sn}$ alloys}

The usually heat treatments for $\mathrm{Sn}$ bronzes are recrystallion (hardened parts) and homogenization (cast parts).

After homogenization the values of mechanical and plasticity characteristics recorded important increases, and from structures of dendrite segregations is obtained monophasic and biphasic homogeneous structures.

In the case of pressure armature, due to constructive configuration of parts and elaboration conditions of alloys, in some areas can appear cracks, these being noseals areas at $8 . .16$ atmosphere pressure.

The bronze quenching is similar to martensitic quenching of steels, obtaining structure with acicular aspect, similar with martensitic structure.

The recommended values of parameters by heat treatments for CuPb12Sn6 alloy is presented in Table 1. Based on these values, we adopted the adopted parameters used in experimental tests.

Table 1. The parameters of heat treatments recommended for $\mathrm{CuPb} 12 \mathrm{Sn} 6$ alloy

\begin{tabular}{|l|c|c|c|}
\hline \multicolumn{1}{|c|}{ The heat treatment } & $\begin{array}{c}\text { The heating } \\
\left.\text { temperature, }{ }^{\circ} \mathbf{C}\right]\end{array}$ & $\begin{array}{c}\text { The maintaining } \\
\text { time },[\mathbf{h}]\end{array}$ & $\begin{array}{c}\text { The cooling } \\
\text { medium }\end{array}$ \\
\hline Homogenization & $700 \ldots 750$ & $1 \ldots 2$ & Free air \\
\hline Recrystallization & $500 \ldots 675$ & $1 \ldots 2$ & Free air \\
\hline Quenching & $>600$ & $0.5 \ldots 1$ & water \\
\hline
\end{tabular}

The heat treatments effectuated in the experimental study, were made in an electric furnace, with resistors, type UTTIS, with fixed hearth.

The adopted parameters (Table 2), for the 3 heat treatments, were controlled with a specific software, type Protherm 100.

Table 2. The parameters of heat treatments adopted for $\mathrm{CuPb} 12 \mathrm{Sn} 6$ alloy

\begin{tabular}{|l|c|c|c|c|}
\hline $\begin{array}{c}\text { The heat } \\
\text { treatment }\end{array}$ & $\begin{array}{c}\text { The heating } \\
\text { temperature, }{ }^{\circ} \mathbf{C}\end{array}$ & $\begin{array}{c}\text { Heating } \\
\text { speed, } \\
\text { '} \mathbf{C} / \text { min }\end{array}$ & $\begin{array}{c}\text { The } \\
\text { maintaining } \\
\text { time, } \mathbf{h}\end{array}$ & $\begin{array}{c}\text { The cooling } \\
\text { medium }\end{array}$ \\
\hline Homogenization & 750 & 10 & 1 & With the furnace \\
\hline Recrystallization & 650 & 10 & 2 & Free air \\
\hline Quenching & 630 & 10 & 1 & water \\
\hline
\end{tabular}




\subsection{The microstructure analysis by electronic microscopy}

The analysis were made on a electronic microscope, SEM model VEGA II LSH, manufactured by Tescan Company of Czech, coupled with a EDX detector, type QUANTAX QX2, manufactured by ROENTEC Company of Germany.

The SEM images were obtained after the samples were previously prepared by polishing on abrasive papers and moistened felt with solution by $\mathrm{Al}_{2} \mathrm{O}_{3}$ powder.

Subsequent, the samples were attacked with a chemical reactive, with the following composition: $5 \mathrm{~g}$ ferric chloride $+30 \mathrm{ml} \mathrm{HCl}+100 \mathrm{ml}$ water, at a maintaining time between $5-10$ seconds.

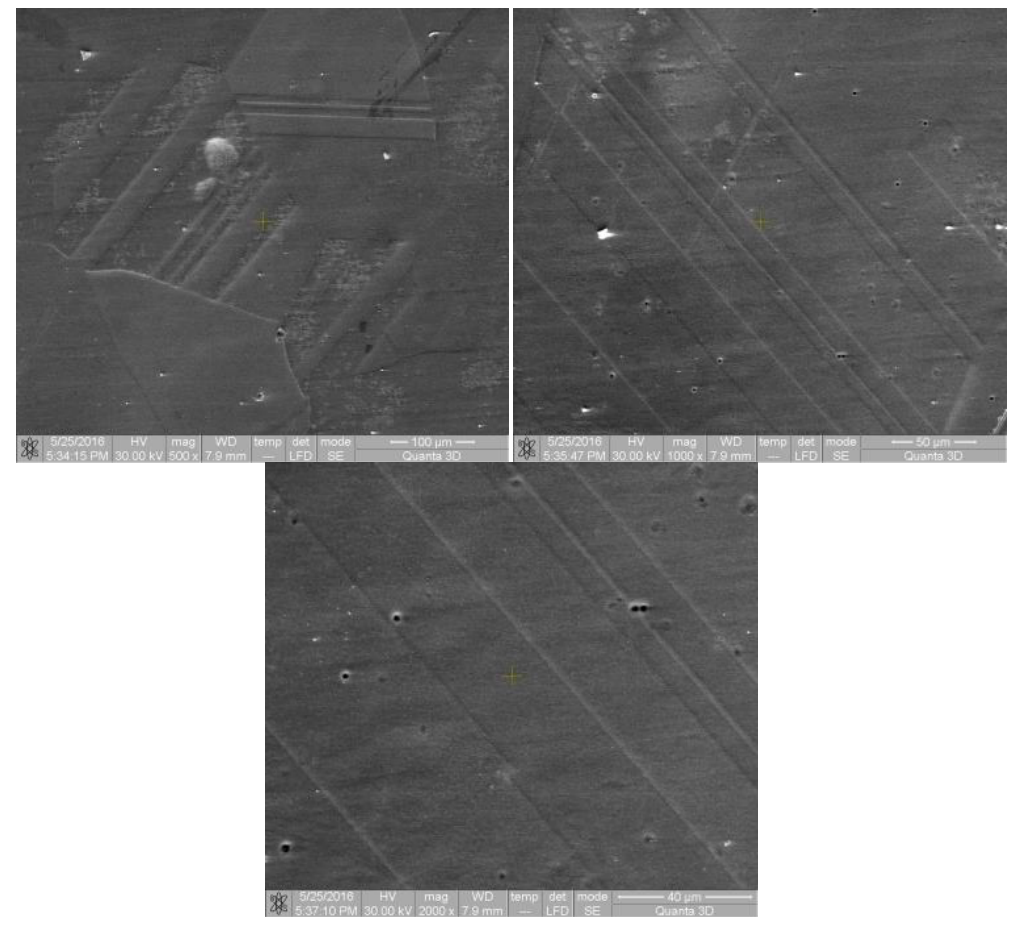

Fig. 2. SEM Microstructure - CuPb12Sn6 alloy - after homogenization heat treatment 


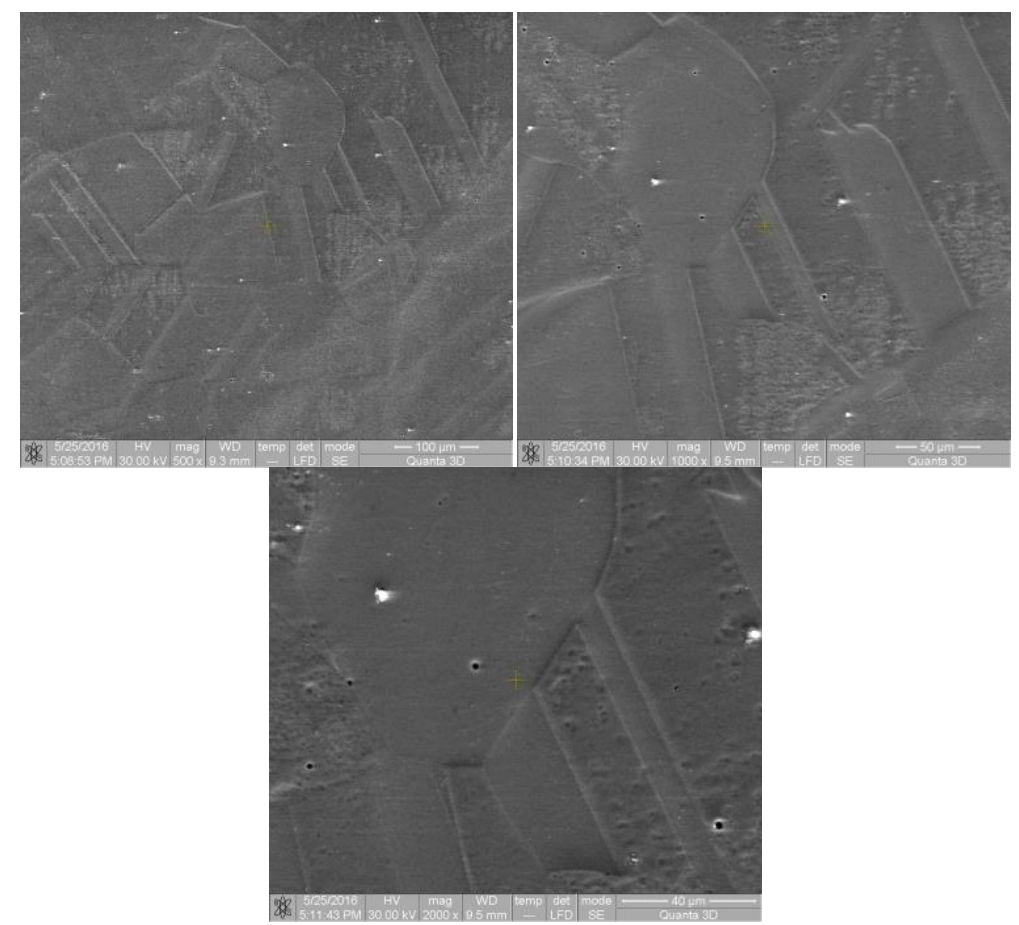

Fig. 3. SEM Microstructure - CuPb12Sn6 alloy - after recrystallization heat treatment

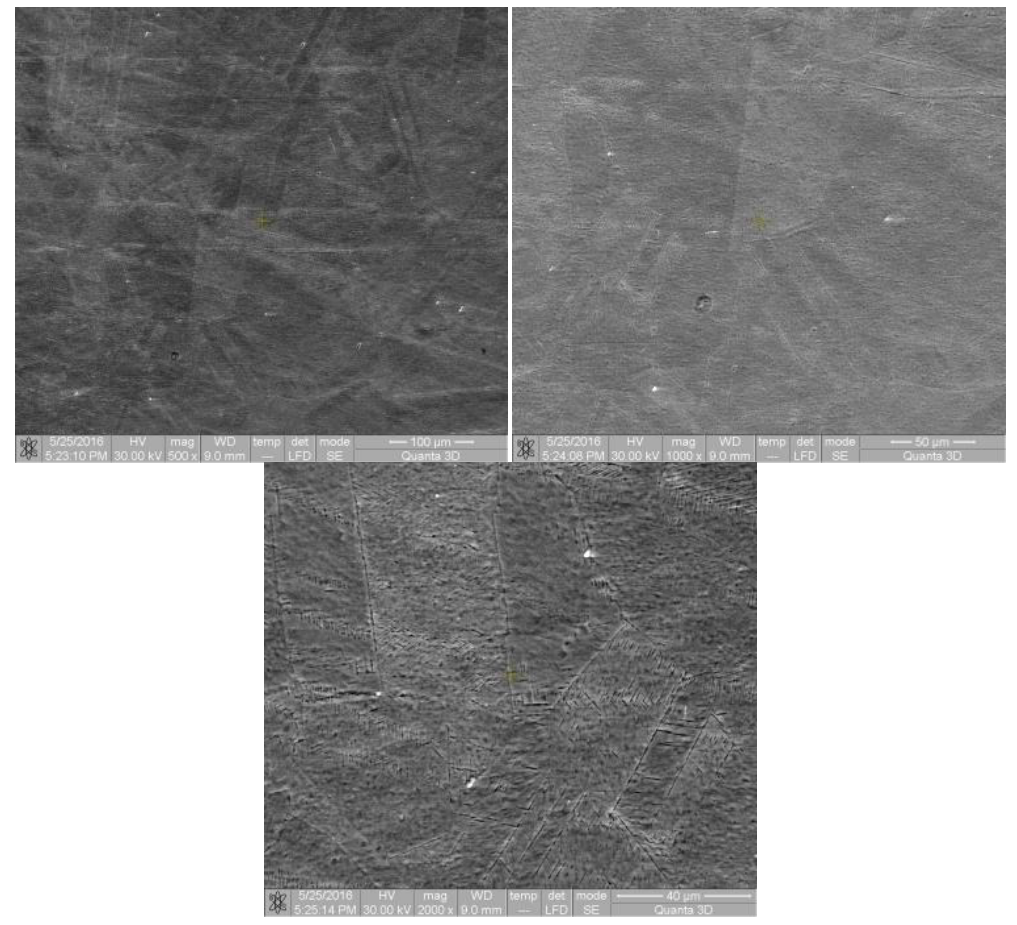

Fig. 4. $\mathrm{SEM}$ Microstructure $-\mathrm{CuPb} 12 \mathrm{Sn} 6$ alloy - after quenching heat treatment 
The microstructure obtained after applying the heat treatments by homogenization (Figure 2) and recrystallization (Figure 3), present a polyhedral homogeneous structure, intertwined by macle.

After quenching, from the microstructure images can observe a solid solution $\delta$ (light color) and eutectoid $(\alpha+\delta)$.

\subsection{The determination of micro-hardness characteristic}

Micro-hardness measurements were performed on PMT3 micro-hardness device, with standard measure of hardness HV 50, using a force measuring $50 \mathrm{~g}$ and a measurement time of 15 seconds.

Were conducted a total of 3 measurements for alloy (Table 3), with the following measuring conditions: temperature $28^{\circ} \mathrm{C}$ (reference temperature: $23 \pm 5^{\circ} \mathrm{C}$ ) and humidity of $62 \%$.

Table 3. Micro-hardness of the CuPb12Sn6 bronzes

\begin{tabular}{|c|c|c|c|c|}
\hline Nr. & $\mathbf{N}$ [div] & $\mathbf{P}[g]$ & HV & average value \\
\hline \multicolumn{5}{|c|}{ After homogenization } \\
\hline 1 & 79 & 50 & 160,23 & \multirow{3}{*}{148,05} \\
\hline 2 & 86 & 50 & 135,20 & \\
\hline 3 & 82 & 50 & 148,72 & \\
\hline \multicolumn{5}{|c|}{ After recrystallization } \\
\hline 1 & 77 & 50 & 168,66 & \multirow{3}{*}{158,01} \\
\hline 2 & 79 & 50 & 160,23 & \\
\hline 3 & 83 & 50 & 145,15 & \\
\hline \multicolumn{5}{|c|}{ After quenching } \\
\hline 1 & 76 & 50 & 173,13 & \multirow{3}{*}{166,96} \\
\hline 2 & 74 & 50 & 182,61 & \\
\hline 3 & 83 & 50 & 145,15 & \\
\hline
\end{tabular}

The obtained values for micro-hardness measurement have specific values of copper alloys, fact which permits an ease processing by cutting, to obtain finite parts with various configurations.

The obtained values for samples in quenching state have a medium micro-hardness by 167 HV50, fact which permit the use of these for manufacturing of supplies parts used in automotive industry, like bushings with collar.

\section{Conclusions}

By homogenization can modify the properties and structure obtained after the cast.

By recrystallization can remove the effects of cutting processing. The structural modifications induced will permit the supplementary processing up to final form of the part, or the final thermal processing.

The obtained structures after quenching, also average values of micro-hardness, permit utilization of studied alloys for manufacture the automotive parts. After a quenching, the structure is thus modified that is obtained a base mass formed preponderant from copper 
base compounds, but can appear lead grains. The hardness of $(\alpha+\delta)$ eutectoid make that alloyed bronzes with $\mathrm{Sn}$ and $\mathrm{Pb}$, in the cast state, to be proper for manufacturing of bearings. The mechanical properties demonstrated by micro-hardness analysis on treated samples, offer to bushings like advantages an easy processing by: casting, forging, cutting, rectification. The principal economical condition is that the final part to present a low cost, the bushings being considers the suppliers' elements in automotive industry.

\section{References}

1. V.J. Keast, J. Ewald, K.S.B. De Silva, M.B. Cortie, B. Monnier, D. Cuskelly, E.H. Kisi, J. Alloys Compd., 647, 129 (2015)

2. A. Fattah-Alhosseini, A.H. Taheri, J Manuf Process, 20, 98 (2015)

3. O.A. Chikova, O.P. Moskovskikh, V.S. Tsepelev, J. Phys. Chem., A, 90, 783 (2016)

4. C. Nobel, U. Hofmann, F. Klocke, D. Veselovac, H. Puls, Wear, 344, 58 (2015)

5. H.S. Wang, H.G. Chen, J.W. Gu, C.E. Hsu, C.Y. Wu, J. Alloys Compd., 633, 59 (2015)

6. G. Enciu, I. Paunescu, Mat. Plast., 52, 564 (2015)

7. M.G. Minciuna, P. Vizureanu, Metal. Int., 18, 123 (2013)

8. M.G. Minciuna, P Vizureanu, D.C. Achitei, N. Ghiban, A.V. Sandu, N.C. Forna, Rev. Chim., 65, 335 (2014)

9. T. Konkova, S. Mironov, A. Korznikov, G. Korznikova, M.M. Myshlyaev, S.L. Semiatin, Mater. Des., 86, 913 (2015)

10. C. Liang, M. Ma, D. Zhang, Mater. Res., 18, 158 (2015)

11. D.C. Achiţei, P. Vizureanu, A.A. Minea, M.M. Al Bakri Abdullah, M.G. Minciună, A.V. Sandu, Appl. Mech. Mater., 657, 412 (2014)

12. V.P. Paun, N.I.C.A.N.O.R. Cimpoesu, R.H. Cimpoesu, G.V. Munceleanu, N. Forna, M. Agop, Mat. Plast., 47, 158 (2010)

13. I. Carcea, M. Gherghe, Editura Performantica, (Iași, 2009)

14. G. Barbu, Tehnologia turnării, (Editura Universitas XXI, Iași, 2008)

15. P. Vizureanu, Sisteme termice inteligente, (Editura P.I.M., Iași, 2013)

16. F. Diaconescu, I. Carcea, Obținerea pieselor prin turnare în forme speciale, (Editura Performantica, Iași, 2012) 